This item was submitted to Loughborough's Research Repository by the author.

Items in Figshare are protected by copyright, with all rights reserved, unless otherwise indicated.

\title{
Improved analytical prediction of chip formation in orthogonal cutting of titanium alloy Ti6Al4V
}

PLEASE CITE THE PUBLISHED VERSION

https://doi.org/10.1016/j.ijmecsci.2017.08.054

\section{PUBLISHER}

(C) Elsevier

VERSION

AM (Accepted Manuscript)

\section{PUBLISHER STATEMENT}

This work is made available according to the conditions of the Creative Commons Attribution-NonCommercialNoDerivatives 4.0 International (CC BY-NC-ND 4.0) licence. Full details of this licence are available at: https://creativecommons.org/licenses/by-nc-nd/4.0/

\section{LICENCE}

CC BY-NC-ND 4.0

\section{REPOSITORY RECORD}

Bai, Wei, Ronglei Sun, Anish Roy, and Vadim V. Silberschmidt. 2019. "Improved Analytical Prediction of Chip Formation in Orthogonal Cutting of Titanium Alloy Ti6al4v”. figshare. https://hdl.handle.net/2134/26443. 


\title{
Improved analytical prediction of chip formation in orthogonal cutting of titanium alloy Ti6Al4V
}

\author{
Wei Bai ${ }^{\text {a, b }}$, Ronglei Sun ${ }^{\text {a, }}{ }^{*}$, Anish Roy ${ }^{\text {, }}$, Vadim V. Silberschmidt ${ }^{\text {b }}$ \\ ${ }^{a}$ The State Key Lab of Digital Manufacturing Equipment and Technology, School of Mechanical Science and Engineering, Huazhong University of Science and \\ Technology, Wuhan 430074, China \\ ${ }^{\mathrm{b}}$ Wolfson School of Mechanical, Electrical and Manufacturing Engineering, Loughborough University, Leicestershire LE11 $3 T U$, UK
}

A B S T R A C T

\begin{abstract}
The aim of this paper is to propose an analytical model of chip formation for precise prediction of orthogonal cutting of Ti6Al4V. This alloy is used broadly in aerospace components; hence, prediction of thermomechanical parameters of its orthogonal cutting is crucial for various industrial applications. The suggested analytical model needs only cutting parameters and tool geometry as input; it can predict not only cutting forces but also main features of a primary shear zone and a tool-chip interface. A non-equidistant shear zone model is employed to calculate shear strains and a shear strain rate in the primary shear zone, and a simplified heat-transfer equation is used for temperature. A Calamaz-modified Johnson-Cook material model that accounting for flow softening at high strains and temperature-dependent flow softening is applied to assess shear stresses in the primary shear zone. In addition, a shear-angle solution is modified for Ti6Al4V. At the tool-chip interface, a contact length, equivalent strain and an average temperature rise are defined. Besides, the effect of sliding and apparent friction coefficients is investigated. For a sawtooth chip produced in the cutting process of Ti6Al4V, the segmentedchip formation is analysed. A chip-segmentation frequency and other parameters of the sawtooth chip are also obtained. The predicted results are compared with experimental data with the cutting forces, tool-chip contact length, shear angle and chip-segmentation frequency calculated with the developed analytical model showing a good agreement with the experiments. Thus, this analytical model can elucidate the mechanism of the orthogonal cutting process of Ti6Al4V including predictive capability of continuous and segmented chip formation.
\end{abstract}

\author{
Keywords: \\ Orthogonal cutting \\ Chip formation \\ Analytical model \\ Chip segmentation \\ Titanium alloy
}

\section{Introduction}

Modelling of chip formation in metal cutting has been of interest to researchers and engineers for decades. This interest stems from the need to understand the effect of machining on a workpiece in terms of residual stress induced, surface characteristics, etc. An adequate analytical model for orthogonal cutting could provide benefits in revealing mechanisms of the cutting process as end-users may easily assess machining quality without having to conduct expensive and time-consuming physical or computational experiments.

Titanium alloys, such as Ti6Al4V, is commonly used in aerospace and biomedical applications thanks to their high mechanical, fatigue and corrosion resistances. However, it is a difficult-to-machine material with complicated chip formation that should be assessed accurately.

Oxley [1] summarized several representative models developed to analyse an orthogonal cutting process; a shear-plane model of Ernst and Merchant [2], a slip-line field model of Lee and Schaffer [3], a nonequidistant shear-zone model of Tounsi et al. [4] and some other. Adibi-
Sedeh [5] and Lalwani et al. [6] extended these models to a broader class of materials by incorporating a Johnson-Cook [7] material model; as a result, forces, temperatures and stress fields at primary shear zone can be obtained.

Contact mechanics is of great importance for machining. To this end, several solutions were developed to characterize complexity of a toolchip interface, namely, pure sliding contact, pure sticking contact, or a combination of both. Özel [8] compared five different friction models and found that variable friction models should be more effective. Zorev [9] observed the distributions of normal pressure and shear stresses on a rake face, and proposed a broadly used scheme with a sticking zone and a sliding zone distributed away from a tool tip along its rake face. Childs [10] verified this model with a quick-stop test. Özel et al. [11] modified temperature models suggested by Oxley to evaluate average temperature of a tool-chip interface and proposed a methodology to determine flow stress by considering simplified friction characteristics. Ozlu et al. [12] analysed the sticking and sliding friction regimes quantitatively with cutting and non-cutting tests. Then, Molinari et al. [13] studied

\footnotetext{
* Corresponding author.

E-mail address: ronglei@hust.edu.cn (R. Sun).
} 


\begin{tabular}{|c|c|}
\hline \multicolumn{2}{|l|}{ Nomenclature } \\
\hline$A, B, C, n, m, a, b, d, r$ and $s$ & $\begin{array}{l}\text { material constants of consti- } \\
\text { tutive model }\end{array}$ \\
\hline $\begin{array}{l}A_{1}, A_{2}, \kappa_{1}, \kappa_{2}, \varsigma_{1}, \varsigma_{2}, \varsigma_{3}, \eta_{1} \text { and } \eta_{2} \\
C_{p}\end{array}$ & $\begin{array}{l}\text { constants } \\
\text { thermal capacity }\end{array}$ \\
\hline$f_{\text {seg }}^{p}$ & $\begin{array}{l}\text { chip-segmentation } \\
\text { frequency }\end{array}$ \\
\hline$F$ & friction force \\
\hline$F_{c}$ & cutting force \\
\hline$F_{t}$ & thrust force \\
\hline$F_{s}$ & shear force \\
\hline$h$ & thickness of shear zone \\
\hline$h_{l}$ & $\begin{array}{l}\text { chip thickness at local shear } \\
\text { deformation }\end{array}$ \\
\hline$H$ & $\begin{array}{l}\text { maximum thickness of saw- } \\
\text { tooth chip }\end{array}$ \\
\hline$k$ & $\begin{array}{l}\text { non-equidistant shear coeffi- } \\
\text { cient }\end{array}$ \\
\hline$k_{\text {int }}$ & $\begin{array}{l}\text { shear flow stress in sec- } \\
\text { ondary shear zone }\end{array}$ \\
\hline K & $\begin{array}{l}\text { thermal conductivity of } \\
\text { workpiece }\end{array}$ \\
\hline$L_{C}$ & tool-chip contact length \\
\hline$L_{P}$ & $\begin{array}{l}\text { contact length of sticking } \\
\text { zone }\end{array}$ \\
\hline$p_{0}$ & pressure on tool tip \\
\hline$p_{c}$ & $\begin{array}{l}\text { distance of sawtooth chip } \\
\text { segmentation }\end{array}$ \\
\hline$p_{s b}$ & shear band projection \\
\hline$p\left(y_{c}\right)$ & $\begin{array}{l}\text { pressure distribution at tool- } \\
\text { chip interface }\end{array}$ \\
\hline$q$ & $\begin{array}{l}\text { non-uniform distribution of } \\
\text { tangential velocity in pri- } \\
\text { mary shear zone }\end{array}$ \\
\hline$R_{T}$ & $\begin{array}{l}\text { non-dimensional thermal } \\
\text { number }\end{array}$ \\
\hline$t_{c}$ & chip thickness \\
\hline$t_{u}$ & undeformed chip thickness \\
\hline$T$ & $\begin{array}{l}\text { instantaneous temperature } \\
\text { of workpiece material }\end{array}$ \\
\hline$T_{E F}$ & $\begin{array}{l}\text { temperature at exit of pri- } \\
\text { mary shear zone }\end{array}$ \\
\hline$T_{\text {int }}$ & $\begin{array}{l}\text { average temperature at tool- } \\
\text { chip interface }\end{array}$ \\
\hline$T_{m}$ & melting temperature \\
\hline$T_{r}$ & room temperature \\
\hline$V$ & cutting velocity \\
\hline$V_{c}$ & chip velocity \\
\hline$V_{s}$ & shear velocity \\
\hline$w$ & width of cutting \\
\hline$x, y, z$ & $\begin{array}{l}\text { coordinate system } \mathfrak{R}: x \text { is } \\
\text { parallel to cutting velocity, } \\
y \text { is parallel to feed and } z \text { is } \\
\text { along width of cutting }\end{array}$ \\
\hline$x_{s}, y_{s}, z_{s}$ & $\begin{array}{l}\text { coordinate system } \Re_{s}: x_{s} \text { is } \\
\text { parallel to shear band, } y_{s} \text { is } \\
\text { perpendicular to shear band } \\
\text { and } z_{s} \text { is along width of cut- } \\
\text { ting }\end{array}$ \\
\hline$x_{c}, y_{c}, z_{c}$ & $\begin{array}{l}\text { coordinate system } \mathfrak{R}_{c}: x_{c} \\
\text { is perpendicular to tool-chip } \\
\text { interface, } y_{c} \text { is parallel to }\end{array}$ \\
\hline
\end{tabular}

\begin{tabular}{|c|c|}
\hline & $\begin{array}{l}\text { tool-chip interface and } z_{c} \text { is } \\
\text { along width of cutting }\end{array}$ \\
\hline$\alpha$ & rake angle \\
\hline$\gamma$ & $\begin{array}{l}\text { shear strain in primary shear } \\
\text { zone }\end{array}$ \\
\hline$\dot{\gamma}$ & $\begin{array}{l}\text { shear strain rate in primary } \\
\text { shear zone }\end{array}$ \\
\hline$\dot{\gamma}_{0}$ & $\begin{array}{l}\text { initial shear strain-rate in } \\
\text { primary shear zone }\end{array}$ \\
\hline$\gamma_{A B}$ & $\begin{array}{l}\text { shear strain at primary shear } \\
\text { plane } A B\end{array}$ \\
\hline$\gamma_{\text {int }}$ & $\begin{array}{l}\text { shear strain at tool-chip in- } \\
\text { terface }\end{array}$ \\
\hline$\dot{\gamma}_{\text {int }}$ & $\begin{array}{l}\text { shear strain rate at tool-chip } \\
\text { interface }\end{array}$ \\
\hline$\dot{\gamma}_{m}$ & $\begin{array}{l}\text { maximum shear strain-rate } \\
\text { in primary shear zone }\end{array}$ \\
\hline$\gamma_{M}$ & $\begin{array}{l}\text { maximum shear strain at } \\
\text { tool-chip interface }\end{array}$ \\
\hline$\delta$ & $\begin{array}{l}\text { thickness ratio of secondary } \\
\text { shear zone to chip }\end{array}$ \\
\hline$\delta_{s b}$ & shear band thickness \\
\hline$\Delta T_{C}$ & $\begin{array}{l}\text { average temperature rise in } \\
\text { chip }\end{array}$ \\
\hline$\Delta T_{M}$ & $\begin{array}{l}\text { maximum temperature rise } \\
\text { in chip occurring at interface }\end{array}$ \\
\hline$\dot{\varepsilon}_{0}$ & $\begin{array}{l}\text { initial strain-rate in sec- } \\
\text { ondary shear zone }\end{array}$ \\
\hline$\varepsilon_{\mathrm{int}}$ & strain at tool-chip interface \\
\hline$\dot{\varepsilon}_{\mathrm{int}}$ & $\begin{array}{l}\text { strain rate at tool-chip inter- } \\
\text { face }\end{array}$ \\
\hline$\zeta$ & Taylor-Quinney coefficient \\
\hline$\lambda$ & mean friction angle \\
\hline$\lambda_{h}$ & chip compression ratio \\
\hline$\mu_{a}$ & $\begin{array}{l}\text { apparent (i.e. global) friction } \\
\text { coefficient }\end{array}$ \\
\hline$\mu_{s l}$ & sliding friction coefficient \\
\hline$\xi$ & $\begin{array}{l}\text { pressure-distribution expo- } \\
\text { nent }\end{array}$ \\
\hline$\rho$ & workpiece density \\
\hline$\tau$ & $\begin{array}{l}\text { shear flow stress in primary } \\
\text { shear zone }\end{array}$ \\
\hline$\tau_{A B}$ & $\begin{array}{l}\text { shear stress at primary shear } \\
\text { plane } A B\end{array}$ \\
\hline$\tau_{\text {int }}$ & $\begin{array}{l}\text { shear stress at tool-chip in- } \\
\text { terface }\end{array}$ \\
\hline$\tau_{p s z}$ & $\begin{array}{l}\text { shear stress at exit of pri- } \\
\text { mary shear zone (equal to } \\
\text { shear stress of shear band EF } \\
\tau_{E F} \text { ) }\end{array}$ \\
\hline $\begin{array}{l}\tau_{s y} \\
\phi\end{array}$ & $\begin{array}{l}\text { shear yield stress of material } \\
\text { shear angle }\end{array}$ \\
\hline$\phi_{\text {saw }}$ & sawtooth shear angle \\
\hline$\psi$ & $\begin{array}{l}\text { partition coefficient of } \Delta T_{M} \\
\text { to tool-chip interface }\end{array}$ \\
\hline
\end{tabular}

comprehensively a link between local parameters and overall friction characteristics with numerical and analytical models. Besides, Bahi et al. [14] introduced a transition zone between sliding and sticking zones. However, a simplified model considering main friction characteristics is needed.

Another challenge is an understanding of chip segmentation in machining of Ti6Al4V. Periodic shear bands in a chip are observed to form due to adiabatic shear behaviour. Formation of sawtooth chips is re- 


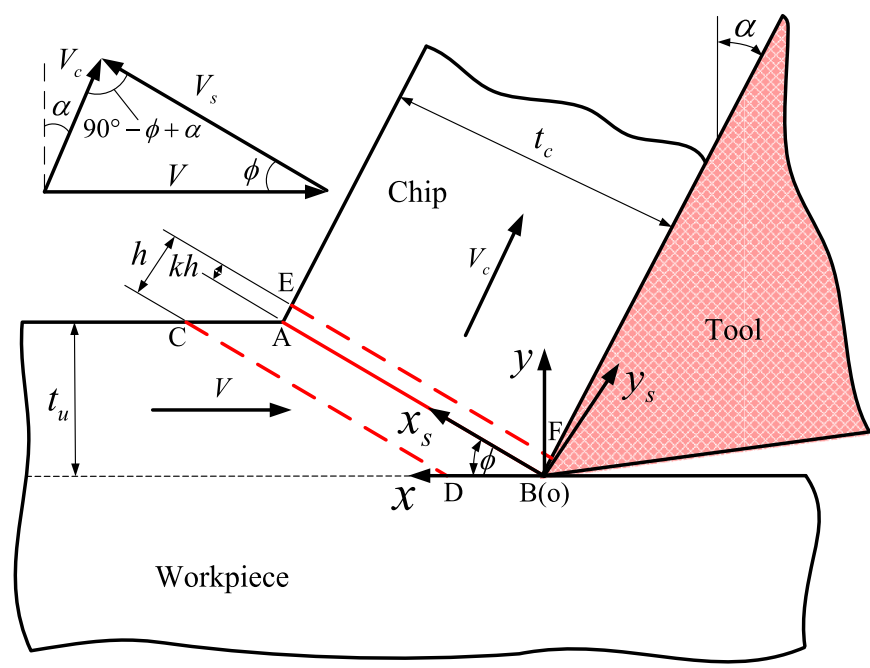

Fig. 1. Schematic diagrams of non-equidistant shear zone model.

sponsible for fluctuations of cutting forces observed in machining. To date, few studies theoretically analysed chip segmentation with complex morphology. Dinzart et al. [15] studied a structure of adiabatic shear bands in thermo-viscoplastic materials. Molinari et al. [16] discussed a shear-band width and a chip-segmentation frequency and proposed an approximated relationship. A thermomechanical shear instability model considering several heat sources was presented by Hou et al. [17]. Some studies used numerical modelling such as finite-element schemes $[18,19]$ to study these phenomena. Hua and Shivpuri [20] performed implicit, Lagrangian, non-isothermal rigid-viscoplastic finiteelement simulations to analyse cracks in chip segmentation. Ducobu et al. [21] assessed chip formation in Ti6Al4V with a numerical model and estimated a teeth-formation frequency. Miguélez et al. [22] and Liu et al. [23] analysed the influence of cutting velocity and feed on chip-segmentation frequency and compared their numerical results with experiments. To the best of authors' knowledge, no analytical model has been proposed for segmented-chip formation that can predict adequately geometrical features of sawtooth chips and the chipsegmentation frequency.

In this study we intend to establish an analytical model for orthogonal cutting allowing relatively simple and accurate predictions of chip formation in Ti6Al4V. In Section 2, numerical modelling of a primary shear zone is introduced. Friction and tool-chip contact conditions are studied in Section 3. By selecting a shear angle from the tool-chip interface, parameters of both primary shear zone and tool-chip interface can be predicted. In Section 4, a model for chip segmentation is proposed based on analysis of geometry and stress-strain states in a sawtooth chip. The results predicted with the developed analytical model are compared with the experimental data in Section 5.

\section{Modelling of primary shear zone}

Modelling deformations in a shear zone of a workpiece in machining is challenging. The non-equidistant shear-zone model of a primary shear zone (PSZ) was proposed by Tounsi et al. [4], based on the parallel-sided shear zone model [1]. The model shows that the shear zone is divided into narrow and wide areas; this was validated by Astakhov et al. [24]. Many researchers [25-27] used this model to predict cutting forces. As shown in Fig. 1, the primary shear zone is a straight band of thickness $h$ (i.e. the region between the inlet boundary $\mathrm{CD}$ and the outlet boundary $\mathrm{EF})$, which is divided by the proportion $k$. And the main shear plane $\mathrm{AB}$, the inlet shear plane $\mathrm{CD}$ and the outlet shear plane EF are parallel. Two coordinate systems are defined, $\mathfrak{R}=\{0, x, y, z\}$ and $\mathfrak{R}_{s}=\left\{0, x_{s}, y_{s}, z_{s}\right\}$.
Table 1

Parameters of Calamaz-modified Johnson-Cook material model for Ti6Al4V alloy.

\begin{tabular}{lllllll} 
Parameters & $A$ & $B$ & $n$ & $C$ & $m$ & \\
\cline { 1 - 5 } Mayer and Kleponis [30] & 862.5 & 331.2 & 0.34 & 0.012 & 0.8 & $a$ \\
Parameters & $b$ & $d$ & $r$ & $s$ & & \\
\cline { 1 - 5 } Sima and Özel [32] & 5 & 1 & 2 & 0.05 & & 0.5 \\
\hline
\end{tabular}

The cutting tool is assumed to be rigid with a sharp edge and rake angle $\alpha$. The undeformed chip thickness and its final magnitude are denoted with $t_{u}$ and $t_{c}$ respectively. The cutting velocity $V$, chip velocity $V_{c}$ and shear velocity $V_{s}$ constitute a triangle as shown in Fig. 1.

To calculate flow stress in the PSZ, the Johnson-Cook [7] material model is widely used. Parameters for this model can be identified with Split-Hopkinson pressure bar tests, or cutting tests, as Lee and Lin [28] for Ti6Al4V. The strain rates range from $0.0001 \mathrm{~s}^{-1}$ to $3000 \mathrm{~s}^{-1}$ with temperature up to $1200^{\circ} \mathrm{C}$, the maximum plastic strain is $0.6 \mathrm{~mm} / \mathrm{mm}$ [28-30] with no consideration for strain-softening. Calamaz et al. [31] modified the Johnson-Cook model by including temperature-dependent flow softening at high strains, so shear stress $\tau$ can be expressed as follows:

$$
\begin{aligned}
\tau= & \frac{1}{\sqrt{3}}\left[A+B\left(\frac{\gamma}{\sqrt{3}}\right)^{n}\left[\frac{1}{\exp \left((\gamma / \sqrt{3})^{a}\right)}\right]\left[1+C \ln \frac{\dot{\gamma}}{\dot{\gamma}_{0}}\right]\right. \\
& \times\left[1-\left(\frac{T-T_{r}}{T_{m}-T_{r}}\right)^{m}\right]\left[D+(1-D)\left[\tanh \left(\frac{1}{(\gamma+p)^{r}}\right)\right]^{s}\right], \\
D= & 1-\left(\frac{T}{T_{m}}\right)^{d}, p=\left(\frac{T}{T_{m}}\right)^{b},
\end{aligned}
$$

where the unknown parameters $A, B, C, n$ and $m$ of the Johnson-Cook material model are obtained from the work of Mayer and Kleponis [30], where the strain rates ranged from $0.0001 \mathrm{~s}^{-1}$ to $2150 \mathrm{~s}^{-1}$ with a strain up to $0.57 \mathrm{~mm} / \mathrm{mm}$. Other material constants $b, d, r$ and $s$ are chosen from Sima and Özel [32], where the experimental data for $A, B, C, n$ and $m$ was obtained by Lee and Lin [28] with lower experimental strains. The parameter $b$ affects the peak flow stress in the temperature-dependent flow softening part, while the parameter $d$ controls an extent of temperature dependency of parameter $D$. The parameter $r$ controls thermal softening and the trend of softening; the parameter $a$ determines the flow softening at high strains in the strain-hardening part; it is chosen as 0.5. The parameters of the Calamaz-modified Johnson-Cook material model for Ti6Al4V alloy are shown in Table 1 . The room temperature $T_{r}$ was $20^{\circ} \mathrm{C}$, and the melting temperature $T_{m}$ is $1660^{\circ} \mathrm{C}$.

In the non-equidistant shear zone model, the levels of shear strain $\gamma$ and shear strain rate $\dot{\gamma}$ can be calculated from [33]:

$\dot{\gamma}= \begin{cases}\frac{\dot{\gamma}_{m}}{[(1-k) h]^{q}}\left[y_{s}+(1-k) h\right]^{q}, & y_{s} \in[-(1-k) h, 0], \\ \frac{\dot{\gamma}_{m}}{(k h)^{q}}\left(k h-y_{s}\right)^{q}, & y_{s} \in[0, k h],\end{cases}$

$\gamma= \begin{cases}\frac{\dot{\gamma}_{m}}{(q+1) V \sin \phi[(1-k) h]^{q}}\left[y_{s}+(1-k) h\right]^{q+1}, & y_{s} \in[-(1-k) h, 0], \\ -\frac{\dot{\gamma}_{m}\left(k h-y_{s}\right)^{q+1}}{(q+1) V \sin \phi(k h)^{q}}+\frac{\cos \alpha}{\cos (\phi-\alpha) \sin \phi}, & y_{s} \in[0, k h],\end{cases}$

$\dot{\gamma}_{m}=\frac{(q+1) V_{s}}{h}=\frac{(q+1) V \cos \alpha}{h \cos (\phi-\alpha)}$,

$k=\frac{\sin \phi \sin (\phi-\alpha)}{\cos \alpha}$,

where $\dot{\gamma}_{m}$ is the maximum shear strain-rate on $\mathrm{AB}, q$ is the non-uniform power-law distribution of tangential velocity in the primary shear zone; it is assumed that $q=3$ for low-velocity cutting [25]. The shear angle 


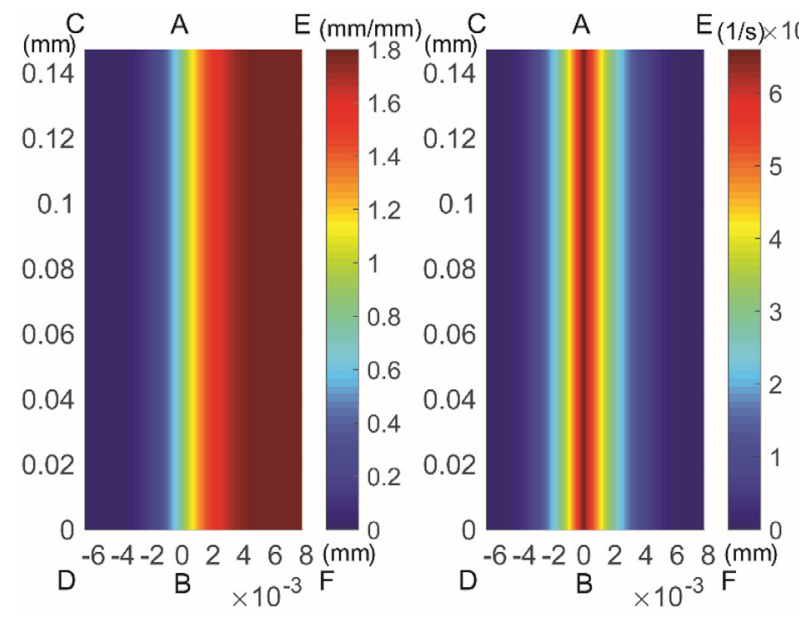

(a) shear strain field (b) shear strain rate field

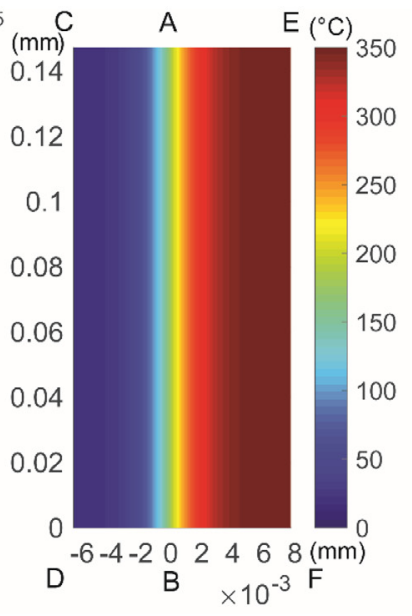

(c) temperature field

Fig. 2. Fields of shear strain, shear strain rate and temperature in primary shear zone, $\left(V=120 \mathrm{~m} / \mathrm{min}, t_{u}=0.1 \mathrm{~mm}\right)$.

is represented by $\phi$. Thickness of shear zone $h$ was proposed by Grzesik [34] as

$h=\frac{t_{u}}{10 \sin \phi}$.

In the PSZ, the shear zone may be regarded as a heat source, where instantaneous temperature $T$ can be calculated from a well-known heat transfer equation [25]. A diffusion term can be ignored because of a high temperature and a small spatial scale in the shear zone. In a steady state, the derivative of temperature is zero. Thus, the heat transfer equation can be simplified with only convective and heat source term as

$\frac{d T}{d y_{s}}=\frac{\zeta \tau \dot{\gamma}}{\rho C_{p} V \sin \phi}$,

where $\zeta$ is the Taylor-Quinney coefficient, $\rho$ is the workpiece density, $C_{p}$ is its thermal capacity. A temperature distribution in the shear zone can be obtained by integrating overy . $_{\text {. }}$

Ignoring minor variations of length of $\mathrm{AB}, \mathrm{CD}$ and $\mathrm{EF}$ in the narrow shear zone, the shear strain, shear strain rate and temperature field can be calculated from Eqs. (2)-(7) (Fig. 2). The maximum shear strain-rate appears in primary shear plane $\mathrm{AB}$, with the shear strain and temperature increasing from $\mathrm{CD}$ to $\mathrm{EF}$ with the movement of material from undeformed workpiece to the deformed chip.

To solve the equation, the shear angle $\phi$ should be defined. Moufki et al. [35] proposed a model for the shear angle model as:

$\phi=A_{1}+A_{2}(\alpha-\lambda)$,

where $\lambda$ is the mean friction angle at the tool-chip interface (discussed in Section 3), $A_{1}$ and $A_{2}$ are material constants to be identified in experiments.

Two additional equations were broadly used for many types of materials to represent the relationship between $\phi, \alpha$ and the apparent friction angle $\lambda$. Ernst and Merchant [2] and Lee and Shaffer [3] proposed shearangle relations successively as:

$\phi=\frac{\pi}{4}+\frac{\alpha-\lambda}{2}$,

$\phi=\frac{\pi}{4}+\alpha-\lambda$.

However, these two solutions are not applicable to all materials.

Fig. 3 shows experimental results for the shear angle in aluminium alloys, brass and titanium alloy. Straight line I represents the relation obtained from the model by Ernst and Merchant (i.e. Eq. (9)) and line II represents the relation based on the model by Lee and Shaffer (i.e. Eq. (10)). Both models predict the response of 2024-T4 and 6061-T6

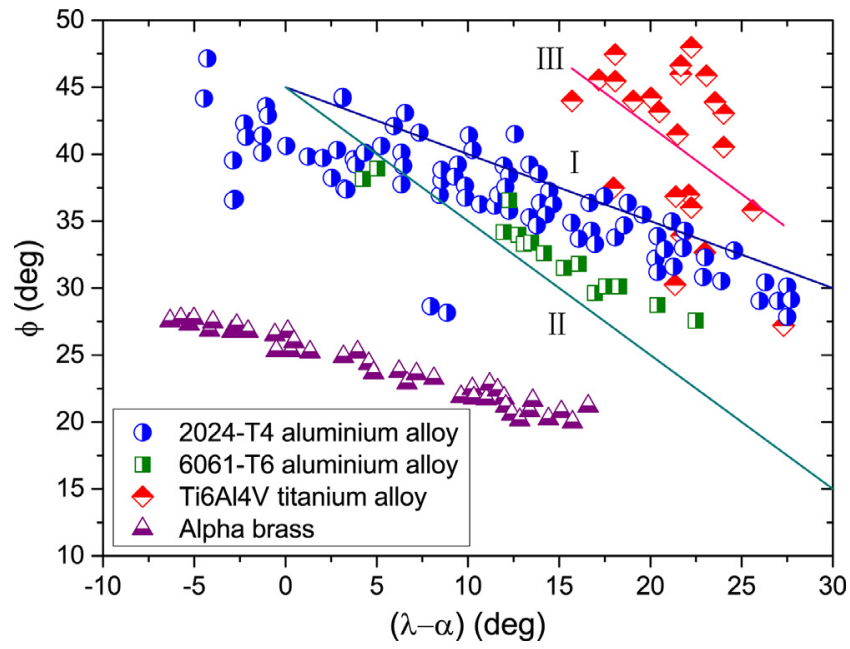

Fig. 3. Experimental shear-angle results $[1,36-38]$.

aluminium alloys reasonably well. However, predictions for alpha brass and Ti6Al4V alloy are poor. Experimental results for Ti6Al4V used here are from Cotterell and Byrne [36-38]. A least-square fit of the data was carried out; it is represented by line III. This fitted line may now be used to establish the relation between $\phi$ and $\alpha-\lambda$ in Eq. (8), from which material constants $A_{1}$ and $A_{2}$ were obtained as $61^{\circ}$ and -1 , respectively.

\section{Analytical model for tool-chip interface}

Here, the dual-zone modelling approach is implemented to represent the shear-zone mechanics between the chip and the rake face the tool [39]. Essentially, the tool-chip interface is divided into a sticking zone and a sliding zone as shown in Fig. 4. In the former, a tool-chip contact condition is assumed to be of plastic deformation due to high normal pressure exerted on the tool, with the contact length $L_{P}$. Consequently, the contact condition is assumed to be elastic in the sliding zone with a contact length of $L_{C}-L_{P}$, where $L_{C}$ is the total tool-chip contact length. Another coordinate system $\mathfrak{R}_{c}=\left\{0, x_{c}, y_{c}, z_{c}\right\}$ is defined, where $y_{c}$ is in the direction of tool-chip interface from the tool tip and $x_{c}$ is perpendicular to the tool-rake face. Thus, the direction of $x_{c}$ has an inclination $\phi-\alpha$ to shear band $\mathrm{AB}$.

As shown in Fig. 4, the secondary shear zone (SSZ) has a length of $L_{P}$ and thickness of $\delta t_{c}$, where $\delta$ is a thickness ratio assumed to be 0.05 


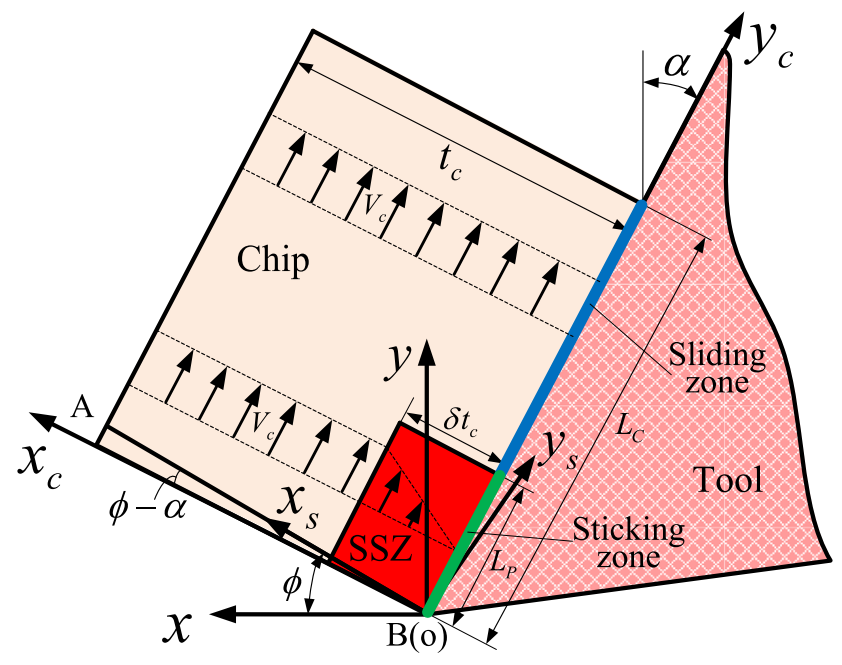

Fig. 4. Illustration of tool-chip interface.

according to the study by Mathew and Oxley [40]. The chip thickness can be expressed as

$t_{c}=t_{u} \frac{\cos (\phi-\alpha)}{\sin \phi}$.

The chip velocity $V_{c}$ is assumed to be uniform in the chip except for the region spanning the SSZ, where the chip velocity decreases in the $-x_{c}$ direction, with the chip velocity vanishing at the sticking zone. Besides, several experimental results showed that the normal pressure decreased along the tool's rake face $[41,42]$. Thus, the pressure distribution $p\left(y_{c}\right)$ at the tool-chip interface is assumed to be

$p\left(y_{c}\right)=p_{0}\left(1-\frac{y_{c}}{L_{C}}\right)^{\xi}$,

where $p_{0}$ is the pressure on the tool tip. The coordinate $y_{c}$ is the distance from the tool tip along the tool-chip interface. The pressure-distribution exponent $\xi$ is assumed as 2 according to Childs et al. [43].

Based on chip equilibrium [35], $p_{0}$ may be expressed as

$p_{0}=4 \frac{1+\xi}{2+\xi} \frac{\cos ^{2} \lambda}{\sin (2(\phi+\lambda-\alpha))} \tau_{p s z}$,

where $\tau_{p s z}$ is the magnitude of shear stress at the exit of the primary shear zone. Thus, $\tau_{p s z}$ equals to the shear stress of the shear band $\mathrm{EF} \tau_{E F}$, obtained in Section 2. The global friction angle, $\lambda$, can be calculated as $\tan ^{-1} \mu_{a}$, where $\mu_{a}$ is the apparent (i.e. global) friction coefficient.

The tool-chip contact length is determined using the relation proposed by Oxley [1], the final relation is given by

$L_{C}=t_{u} \frac{\sin (\phi+\lambda-\alpha)}{\sin \phi \cos \lambda}\left(\frac{2}{3}+\frac{1+2(\pi / 4-\phi)}{3 \tan (\phi+\lambda-\alpha)}\right)$

Another relation for $L_{C}$ [35] was widely used for many materials $[12,44]$ :

$L_{C}=t_{u} \frac{2+\xi}{2} \frac{\sin (\phi+\lambda-\alpha)}{\sin \phi \cos \lambda}$.

However, the studies indicate that the tool-chip contact length in Eq. (15) overestimates the results experimentally determined for Ti6Al4V irrespective of the choice of $\xi$. Eq. (14) is more suitable for Ti6Al4V than Eq. (15) to predict $L_{C}$ as shown in Section 5.

The relationship between the apparent friction coefficient $\mu_{a}$ and the sliding friction coefficient $\mu_{s l}$ is obtained by Budak and Ozlu [39]. In our proposed model, for a given initial value of $\mu_{a}$, the sliding friction coefficient $\mu_{s l}$ and the length of sticking zone $L_{P}$ can be calculated as

$\mu_{s l}=\frac{\tau_{s y}}{p_{0}} \frac{1}{\left[1-\frac{1}{\xi}\left(\frac{\mu_{a} p_{0}}{\tau_{s y}}-1\right)\right]^{\xi}}$,
$L_{P}=L_{C}\left(1-\left(\frac{\tau_{s y}}{p_{0} \mu_{s l}}\right)^{1 / \xi}\right)$,

where $\tau_{s y}$ is the shear yield stress of the material, which is also equal to the shear stress at the exit of the primary shear zone $\tau_{E F}$.

The calculated values of the contact length and friction at the toolchip interface are shown in Fig. 5(a) for different cutting speeds and feeds (i.e. the same value of undeformed chip thickness $t_{u}$ ). The toolchip contact length $L_{C}$ and sticking contact length $L_{P}$ decrease slowly with cutting speed and increase with feed. Obviously, the feed has a more significant effect on $L_{C}$ than on $L_{P}$. It can also be seen in Fig. 5(b) that the apparent and sliding friction coefficients decrease with cutting speed, and both decrease with increasing feed rate. Another crucial phenomenon is the fact that the sliding friction coefficient is larger than the apparent friction coefficient in different cutting conditions, was validated by Ozlu et al. [12].

The shear stress at the tool-chip interface $\tau_{\text {int }}$ is obtained from the following equation:

$\tau_{\text {int }}=\frac{F}{L_{C} w}=\frac{F_{s}}{L_{C} w} \frac{\sin \lambda}{\cos (\phi+\lambda-\alpha)}$,

where $F$ is the friction force at the tool-chip interface, which can be determined from the geometric relations for the primary shear zone [1]; $F_{s}$ is the shear force along shear plane $\mathrm{AB}$, which is evaluated using

$F_{s}=\frac{w t_{u} \tau_{A B}}{\sin \phi}$,

where $\tau_{A B}$ is the shear stress at the primary shear plane AB.

At the tool-chip interface, the SSZ is assumed to be a rectangular zone of thickness $\delta t_{c}$. The equivalent maximum strain rate is given by the von Mises criterion:

$\dot{\varepsilon}_{\text {int }}=\frac{\dot{\gamma}_{\text {int }}}{\sqrt{3}}=\frac{V_{c}}{\sqrt{3} \delta t_{c}}$.

The equivalent strain at the tool-chip interface is expressed as

$\varepsilon_{\text {int }}=\frac{\gamma_{\text {int }}}{\sqrt{3}}=\frac{\kappa_{1} \gamma_{A B}+\kappa_{2} \gamma_{M}}{\sqrt{3}}$

where $\gamma_{A B}$ is the shear strain at the primary shear plane AB, $\gamma_{M}(=$ $L_{C} / \delta t_{c}$ ) is the maximum shear strain at the tool-chip interface. The shear-strain coefficients $\kappa_{1}$ and $\kappa_{2}$ are chosen as 2 and 0.5 , respectively [6]. However, the numerical modelling of orthogonal cutting based on Sima and Özel [32] was carried out for Ti6Al4V; Fig. 6(a) shows the strain field in the process zone. The numerical model was validated with data from orthogonal cutting experiments with Ti6Al4V at different cutting conditions and in our prior studies $[45,46]$ as well. In the SSZ, the average equivalent strain is $\sim 3$. Based on this, the coefficients $\kappa_{1}$ and $\kappa_{2}$ were modified to 2 and 0.2 , respectively, to fit this material.

The average temperature at the tool-chip interface is calculated as

$T_{\text {int }}=T_{E F}+\psi \Delta T_{M}$,

where $T_{E F}$ is the temperature at the exit of the primary shear zone, $\Delta T_{M}$ is the maximum temperature rise in the chip occurring at the interface, $\psi$ is the partition coefficient of $\Delta T_{M}$ to the tool-chip interface. In addition, $\Delta T_{M}$ can be obtained by assuming a rectangular heat source at the interface as suggested by Boothroyd [47]. Considering the effect of different materials on a temperature rise, the relationship between material properties, tool-chip geometrical dimensions and a temperature rise may be modified as

$$
\begin{aligned}
\log _{10}\left(\frac{\Delta T_{M}}{\Delta T_{C}}\right) & =\varsigma_{1}+\varsigma_{2} \delta \sqrt{\frac{R_{T} t_{c}}{L_{C}}}+\varsigma_{3} \log _{10} \sqrt{\frac{R_{T} t_{c}}{L_{C}}}, \\
\Delta T_{C} & =\frac{F V_{c}}{\rho C_{p} t_{u} w V}, R_{T}=\frac{\rho C_{p} V t_{u}}{K},
\end{aligned}
$$

where $\Delta T_{C}$ is average temperature rise in the chip, $R_{T}$ is the nondimensional thermal number, $K$ is the thermal conductivity of the 

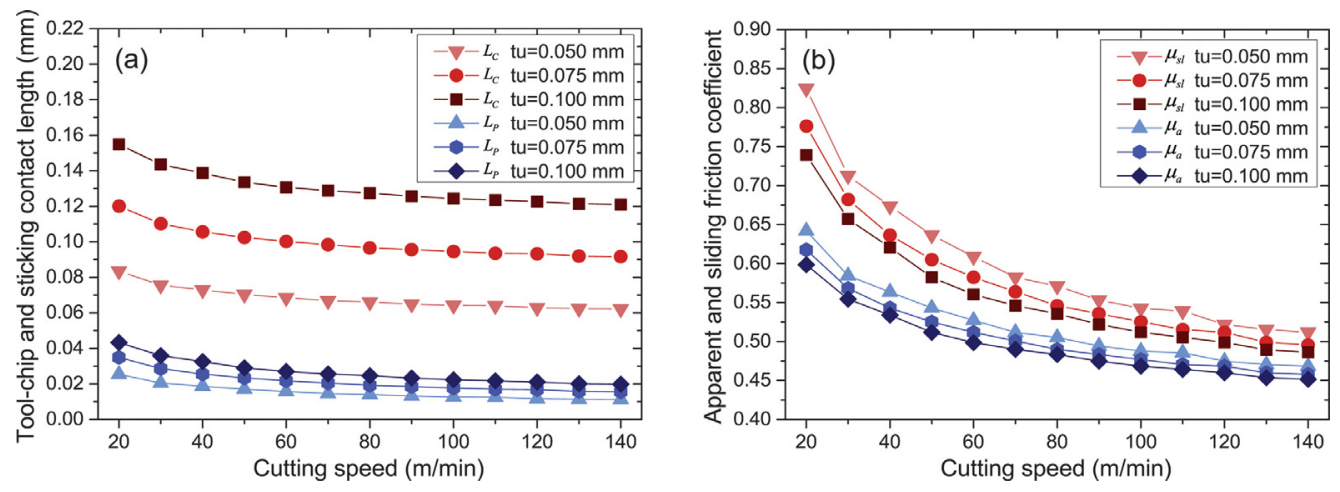

Fig. 5. Contact length (a) and friction coefficient (b) at tool-chip interface for different cutting speeds and feeds.
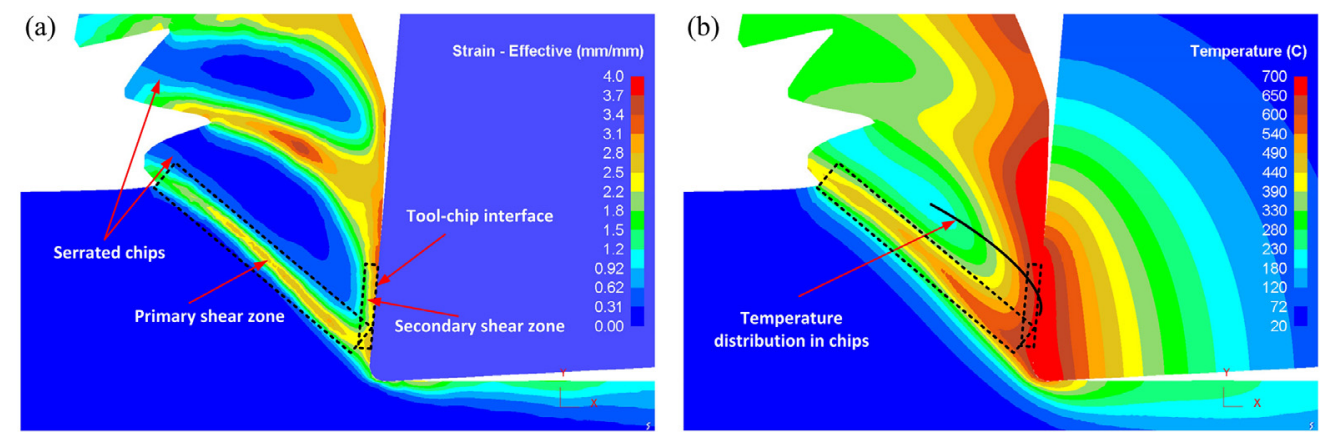

Fig. 6. Numerical modeling results: (a) strain field; (b) temperature field of chip formation at cutting speed of $120 \mathrm{~m} / \mathrm{min}$ and a feed of $0.1 \mathrm{~mm} / \mathrm{rev}$.

workpiece, $w$ is the width of cutting and $\varsigma_{1}, \varsigma_{2}$ and $\varsigma_{3}$ are the material constants. Stevenson [48] summarized the Boothroyd's results as an empirical relation for brass and mild steel, with constants corresponding to $0.06,-0.195$ and 1 in Eq. (23), and the relationship between $\Delta T_{M} \sqrt{L_{C} / R_{T} t_{c}} / \Delta T_{C}$ and $\delta \sqrt{R_{T} t_{c} / L_{C}}$ plotted in [1]. Considering Ti6Al4V, the temperature field of chip formation is shown in Fig. 6(b). Thus, $\varsigma_{3}$ was optimized as 0.56 and $\psi$ was 0.46 , yielding $T_{\text {int }}$ to be close to $700{ }^{\circ} \mathrm{C}$ at the tool-chip interface. Fig. 6 also demonstrates the serrated chips, which is discussed in Section 4.

In the SSZ, the Johnson-Cook constitutive equation is still valid for material behaviour [14]. Based on the above equations, the shear flow stress $k_{\text {int }}$ can be obtained with the Johnson-Cook material model as

$k_{\text {int }}=\frac{1}{\sqrt{3}}\left[A+B \varepsilon_{\text {int }}{ }^{n}\right]\left[1+C \ln \frac{\dot{\varepsilon}_{\text {int }}}{\dot{\varepsilon}_{0}}\right]\left[1-\left(\frac{T_{\text {int }}-T_{r}}{T_{m}-T_{r}}\right)^{m}\right]$,

where, in the secondary shear zone, shear behaviour is less intense than that in the primary shear zone, and the strain rate is far lower than in the latter. So the Johnson-Cook material model is sufficient, without having to employ the modified equation in (1).

The shear stress $\tau_{\text {int }}$ is calculated based on the resultant force at the primary shear plane AB. However, shear flow stress $k_{\text {int }}$ of the material corresponds to the strain, strain rate and temperature at the tool-chip interface. These two variables are both functions of the shear angle. They are described employing mechanical and physical characteristics, which have no essential difference. Thus, the shear angle $\phi$ is selected, when shear stress $\tau_{\text {int }}$ equals the shear flow stress $k_{\text {int }}$ at the tool-chip interface [5]. The variations of $\tau_{\text {int }}$ and $k_{\text {int }}$ with shear angle $\phi$ are shown in Fig. 7 for a cutting speed of $60 \mathrm{~m} / \mathrm{min}$ and a feed of $0.1 \mathrm{~mm} / \mathrm{rev}$. It can be seen that there are two points of intersection of the curves (labelled Intersection I and II in Fig. 7). From a practical standpoint Intersection I is chosen to obtain the shear angle for the reason explained by Oxley [1]. The value of shear angle, $\phi$, is expected to decrease from a relatively high value at the start of the cutting process; thus, the first point of equilibrium would be Intersection I. Additionally, many experimental

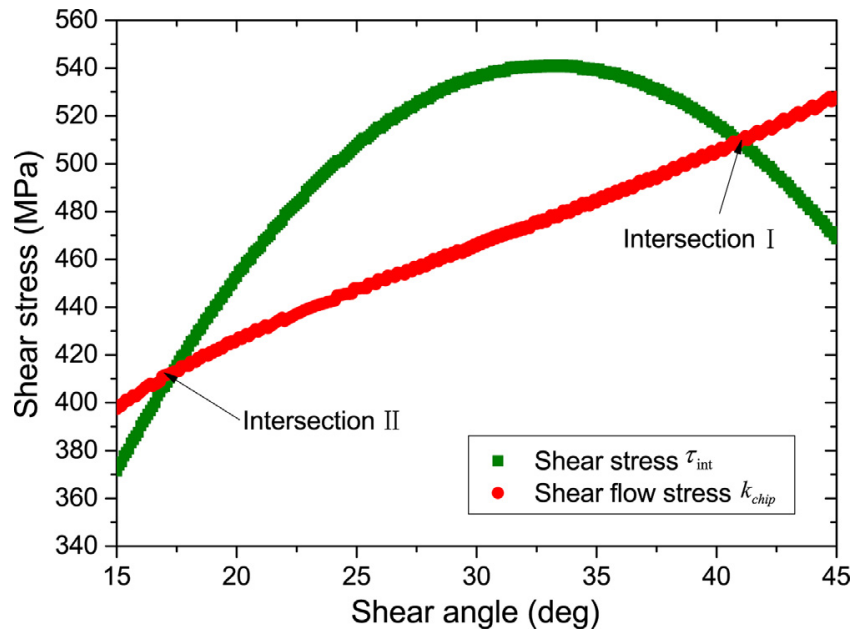

Fig. 7. Variations of $\tau_{\text {int }}$ and $k_{\text {int }}$ with shear angle $\phi$.

results show that the shear angle for Ti6Al4V varies between $30^{\circ}$ and $50^{\circ}[36,49]$. So, the choice of Intersection I is deemed correct.

Thus, the cutting force $F_{c}$ and the thrust force $F_{t}$ can be expressed as

$F_{c}=F_{s} \frac{\cos (\lambda-\alpha)}{\cos (\phi+\lambda-\alpha)}=\frac{w t_{u} \tau_{A B} \cos (\lambda-\alpha)}{\sin \phi \cos (\phi+\lambda-\alpha)}$,

$F_{t}=F_{s} \frac{\sin (\lambda-\alpha)}{\cos (\phi+\lambda-\alpha)}=\frac{w t_{u} \tau_{A B} \sin (\lambda-\alpha)}{\sin \phi \cos (\phi+\lambda-\alpha)}$.

In this section, most variables at the tool-chip interface are calculated with a single value instead of a field as in Section 2 (since these variables do not vary too much) in order to simplify the analysis.

In Sections 2 and 3, an accurate and efficient model for prediction of chip formation was presented. A flow chart of the essential steps followed in the analytical model is shown in Fig. 8. The proposed model is 


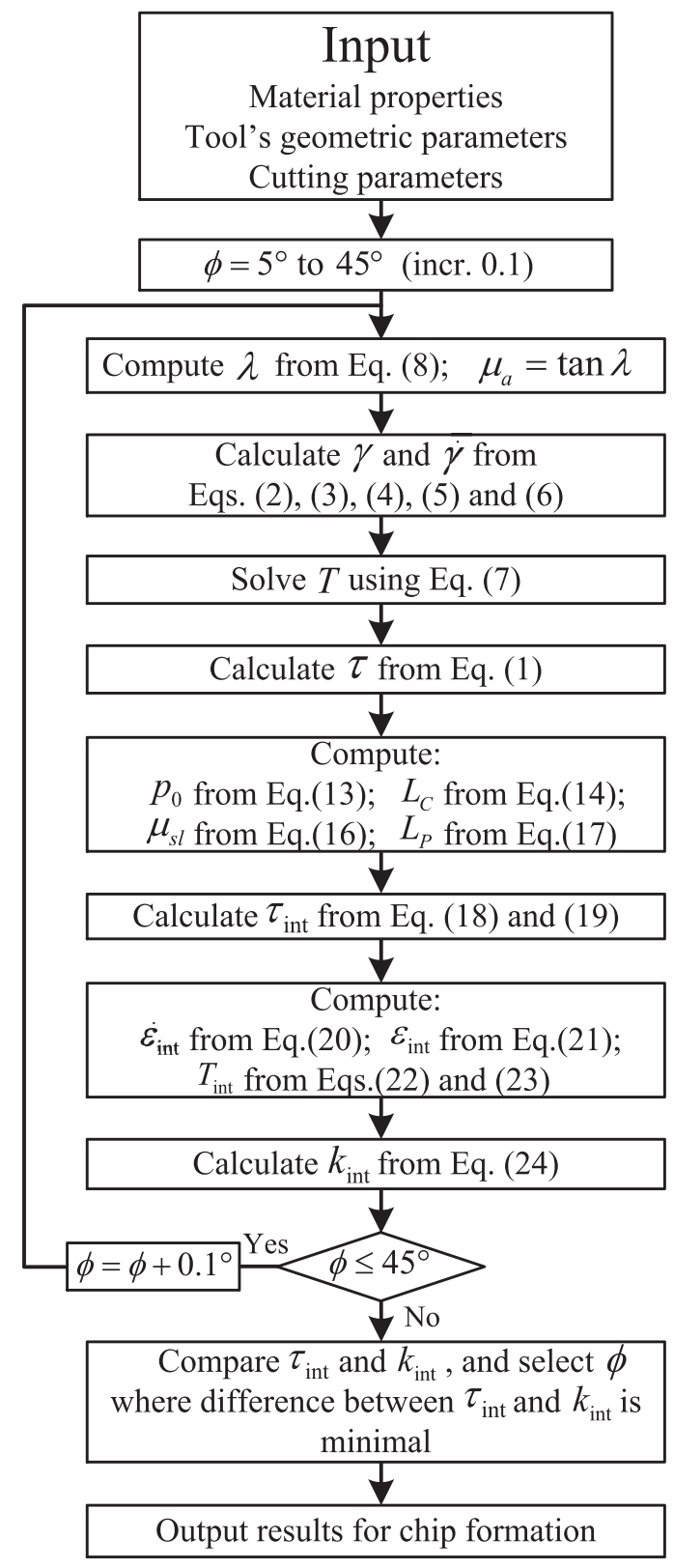

Fig. 8. Flow chart of analytical model for chip formation.

applicable for other metallic materials with suitable parameter calibration.

\section{Modelling of segmented chip formation}

For many difficult-to-machining materials, such as Ti6Al4V, serrated chips are generated in a cutting process. In the chip-formation process, when a critical strain is reached, a shear band is formed. Thus, the resulting chips consist of chip segments separated by narrow bands with thickness of $\delta_{s b}$ as shown in Fig. 9.

In Sections 2 and 3, chip segmentation was not considered in the shear processes in primary and secondary shear zones. Thermomechanical behaviour in shear zone and shear band should have a reciprocal effect. However, these zones are extremely narrow and complex. Parameters investigated mostly in primary and secondary shear zone, e.g. cutting forces, are average values, not accounting for the fluctuations due to formation of a sawtooth chip.

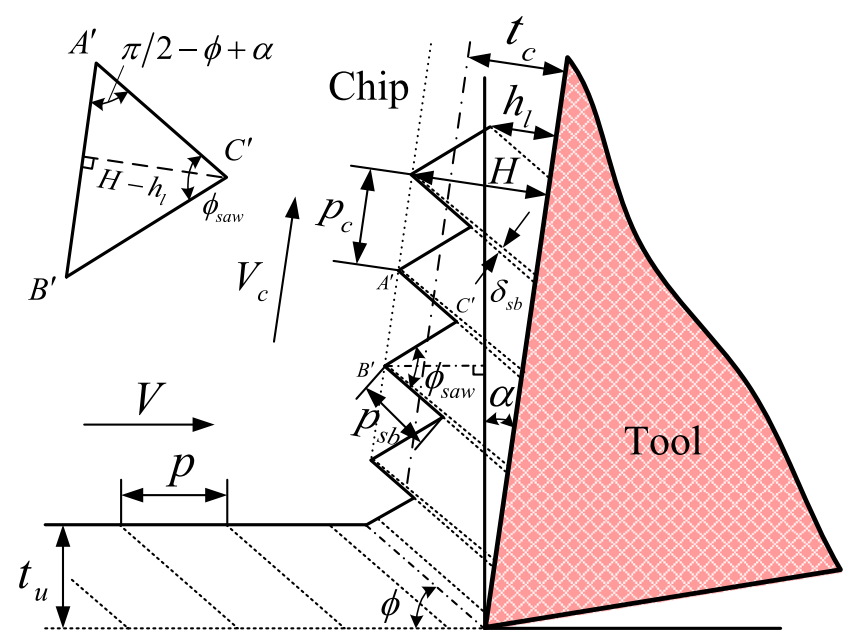

Fig. 9. Diagram of segmented chip.

Geometry of segmented chips can be described using the maximum thickness of sawtooth chip $H$, the chip thickness at local shear deformation $h_{l}$, the sawtooth shear angle $\phi_{\text {saw }}$, the shear band projection $p_{s b}$ and the distance of sawtooth chip segmentation $p_{c}$. The chip compression ratio $\lambda_{h}$ is defined as

$\lambda_{h}=\frac{t_{c}}{t_{u}}=\frac{V}{V_{c}}=\frac{\cos (\phi-\alpha)}{\sin \phi}$,

where the shear angle $\phi$ was determined in Section 3.

The equivalent chip thickness of the segmented chip $t_{c}$ is expressed as

$t_{c}=h_{l}+\frac{H-h_{l}}{2}$.

It consists of two parts: the chip thickness at local shear deformation $h_{l}$ and a trapezoidal chip sawtooth matrix [50].

However, $h_{l}$ is unknown. In this paper, $h_{l}$ is assumed to be a multiple of the equivalent chip thickness $t_{c}$. The linking factor $\eta$ is not a constant but changes with the value of undeformed chip thickness $t_{u}$. Thus, the $h_{l}$ is given by

$h_{l}=\eta t_{c}=\left(\eta_{1}+\eta_{2} t_{u}\right) t_{c}$,

where the coefficients $\eta_{1}$ and $\eta_{2}$ are constants. Here, $h_{l}$ depends on variations in undeformed chip thickness $t_{u}$. By measuring Hand $h_{l}$ from experimental chip morphology Fig. 10) in sawtooth chip with two groups of cutting conditions, $\eta_{1}$ and $\eta_{2}$ were determined as 0.6 and 2 from Eqs. (28) and (29).

The angle between the shear plane and the topside edge of the chip is given by $\phi_{\text {saw }}$, which is an important parameter of segmented chip formation. He et al. [51] analysed shear strains in a chip segment; a material within a parallelogram of the undeformed chip is converted into a trapezoidal shape as a result of tool motion as shown in Fig. 9. Shear strain in the primary shear plane is assumed to be shear strain of the chip segment. Thus, a relationship between shear strain at the primary shear plane $\gamma_{A B}$ and the sawtooth shear angle $\phi_{\text {saw }}$ is given as

$\gamma_{A B}=\frac{1}{\lambda_{h} \sin \phi} \sqrt{\frac{1}{\sin ^{2} \phi}+\lambda_{h}{ }^{2}-2 \lambda_{h} \frac{\cos \left(\phi_{\text {saw }}-\phi\right)}{\sin \phi_{\text {saw }}}}$,

where $\gamma_{A B}$ can be calculated following Section 2 .

The area between two protrusions in the chip formation is represented by triangle $A^{\prime} B^{\prime} C^{\prime}$ (Fig. 9), with its sides $A^{\prime} B^{\prime}$ and $A^{\prime} C^{\prime}$ equal to the distance of sawtooth chip segmentation $p_{c}$ and the shear band projection $p_{s b}$. Thus, the shear band projection $p_{s b}$ can be expressed as

$p_{s b}=\overline{A^{\prime} C^{\prime}}=\frac{H-h_{l}}{\cos (\phi-\alpha)}$. 


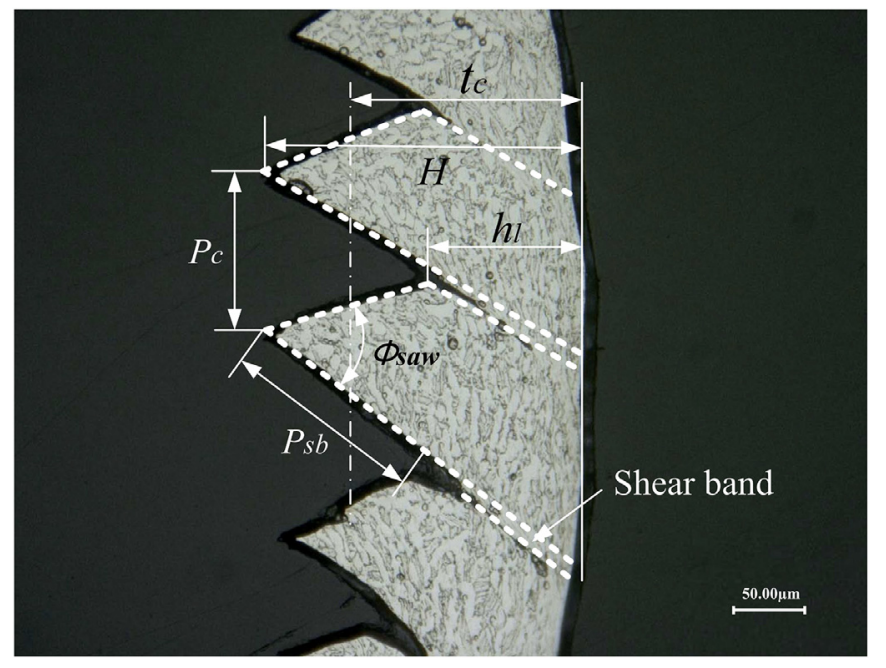

Fig. 10. Chip morphology and measurement of sawtooth chip (cutting speed: $20 \mathrm{~m} / \mathrm{min}$, feed: $0.14 \mathrm{~mm} / \mathrm{rev}$ )

The distance of sawtooth chip segmentation $p_{c}$ can be determined by the law of sines with the relation between the sides and the angles of triangle $A^{\prime} B^{\prime} C^{\prime}$ as

$\frac{p_{c}}{\sin \phi_{\text {saw }}}=\frac{p_{\text {sb }}}{\sin \left(\pi / 2+\phi-\alpha-\phi_{\text {saw }}\right)}$,

where $p_{c}$ can be calculated as

$p_{c}=\frac{\left(H-h_{l}\right) \sin \phi_{\text {saw }}}{\cos (\phi-\alpha) \cos \left(\phi_{\text {saw }}+\alpha-\phi\right)}$.

The chip-segmentation frequency can be expressed as the chip velocity divided by the distance of sawtooth chip:

$f_{\text {seg }}=\frac{V}{\lambda_{h} p_{c}}$.

Based on the above analysis, chip morphology and the chipsegmentation frequency can be predicted. A flow chart of the analytical model for segmented chip formation is shown in Fig. 11.

Fig. 12 shows the maximum thickness of the sawtooth chip and the distance of chip segmentation for different cutting speeds and feeds. The maximum thickness of the sawtooth chip $(H)$ decreases slightly with cutting speed and increases with feed, which is always larger than the undeformed chip thickness. In contrast, the extent of variation of the distance of chip segmentation $\left(p_{c}\right)$ with cutting speed is lower. This parameter retains a nearly constant level of different cutting speeds with a certain degree of chatter. In addition, the higher feeds such as $0.075 \mathrm{~mm} / \mathrm{rev}$ and $0.1 \mathrm{~mm} / \mathrm{rev}$ show similar magnitudes of $p_{c}$ compared to the lower feed of $0.05 \mathrm{~mm} / \mathrm{rev}$. This interesting phenomenon results in the fact

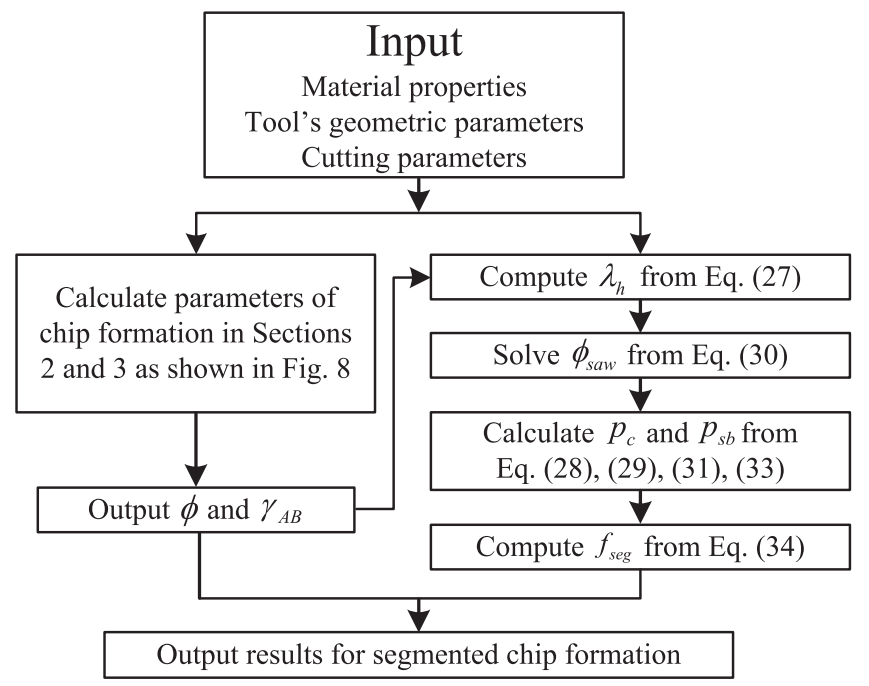

Fig. 11. Flow chart of analytical model for segmented chip formation.

that the chip segmentation frequency varies linearly with cutting speed and has a similar tendency at higher feeds, as validated in Section 5 (see Fig. 18).

\section{Results and discussion}

The developed analytical model of chip formation can predict more parameters than traditional schemes: not only cutting forces, a shear angle, a tool-chip contact length, a chip segmentation frequency, but also characteristics of a primary shear zone and a tool-chip interface. In this section, the proposed model is verified by experimental results of orthogonal cutting tests by Cotterell and Byrne [36-38], performed on a series of $2 \mathrm{~mm}$-thick Ti6Al4V flat disks. The material was in the annealed state with an equiaxed $\alpha-\beta$ microstructure. Uncoated fine-grained WC inserts (TPUN $160308 \mathrm{H} 10 \mathrm{~F}$ ) with a flat rake face and a cutting edge radius of circa $5 \mu \mathrm{m}$ were used as cutting tool. The tool's rake face was at $6.5^{\circ}$. Details of the experiments are available in [35-37].

For our analytical model, the tool parameters were chosen the same as in the experiments, with the cutting speed varied from $20 \mathrm{~m} / \mathrm{min}$ to $140 \mathrm{~m} / \mathrm{min}$, a cutting width of $2 \mathrm{~mm}$. The Taylor-Quinney coefficient of the workpiece $\zeta$ was 0.85 , the workpiece density $\rho$ was $4520 \mathrm{~kg} / \mathrm{m}^{3}$, its thermal capacity $C_{p}$ was $610 \mathrm{~J} /(\mathrm{kg} \mathrm{K})$ and thermal conductivity $K$ was $7 \mathrm{~W} /(\mathrm{m} \mathrm{K})[14]$.

Fig. 13 shows a comparison of predicted cutting force $F_{c}$ and thrust force $F_{t}$ with the experimental data for different cutting speeds at feeds of $0.05,0.075$ and $0.1 \mathrm{~mm} / \mathrm{rev}$. Apparently, the predicted forces corresponds well with the experimental results, especially for the cutting
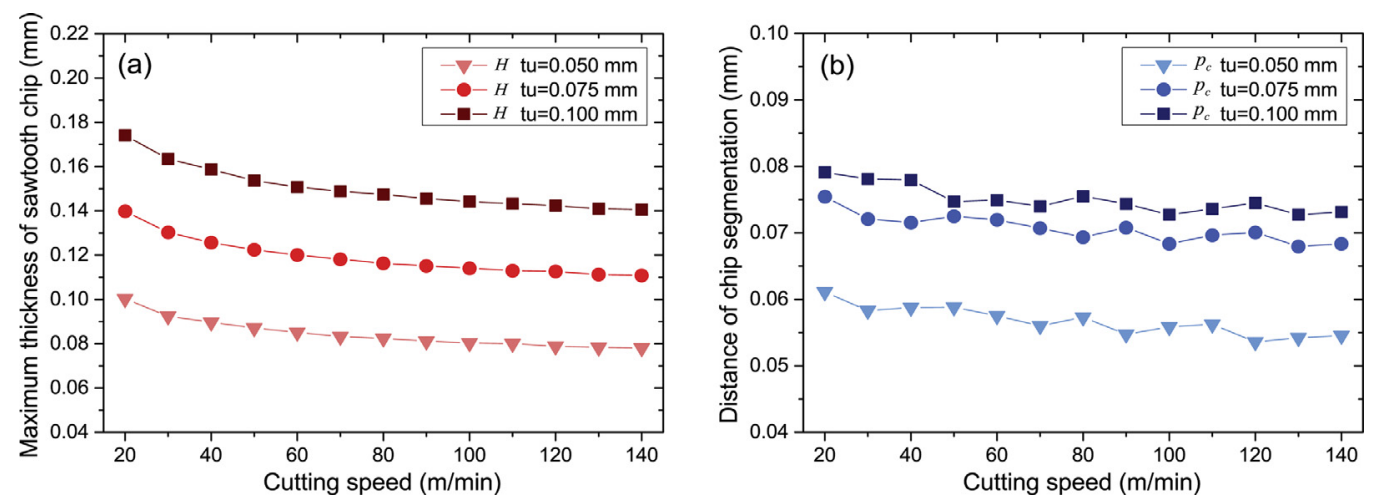

Fig. 12. Maximum thickness of sawtooth chip (a) and distance of chip segmentation (b) for different cutting speeds and feeds. 

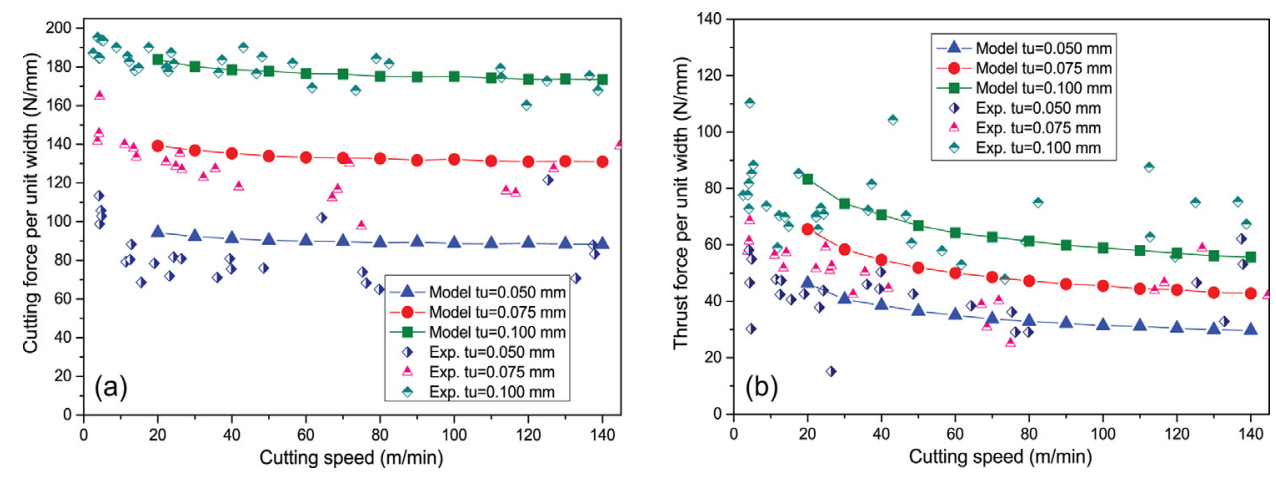

Fig. 13. Comparison of predicted cutting (a) and thrust (b) forces with experimental data [38] for different cutting speeds at feeds of 0.05 , 0.075 and 0.1 mm/rev.

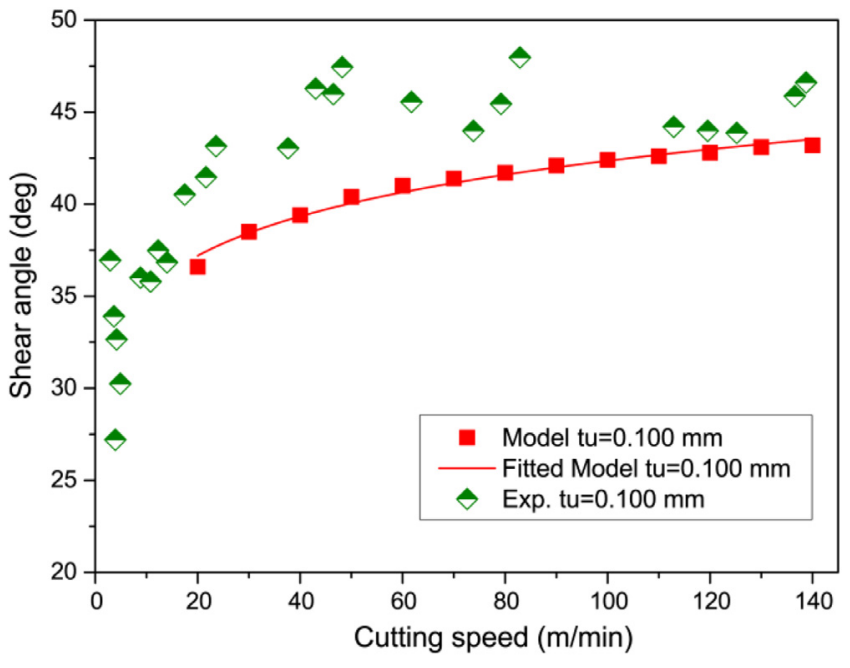

Fig. 14. Comparison of predicted shear angle with experimental data [37] for different cutting speeds at feed of $0.1 \mathrm{~mm} / \mathrm{rev}$.

forces. Both types of forces decreased with an increase in the cutting speed. However, the cutting forces decreased more slightly than the thrust ones. Both the cutting and thrust forces increase with an increase in feed. Obviously, the experimentally measured thrust forces have a larger variation, since continual tool wear affected the tool-chip friction, the cutting-edge radius and the distribution of resultant forces.

The shear-angle magnitude $\phi$ calculated with the model was also compared with the experimental data (Fig. 14). It can be seen that this parameter increased with an increase in the cutting speed up to about $45^{\circ}$. The experimental data for apparent shear angles for a feed of $0.1 \mathrm{~mm} / \mathrm{rev}$ was determined from the chip-velocity data. The experimental shear angles had a degree of scatter with magnitudes higher than the analytically predicted values. Still, the predicted trends are reasonable considering a spread of experimental results.

The tool-chip contact length $L_{C}$ was determined from measurements of video image obtained with a high-speed monochrome camera. The experimental and predicted results are shown in Fig. 15. The tool-chip contact length decreased from $0.16 \mathrm{~mm}$ to $0.12 \mathrm{~mm}$. Therefore, for Ti6Al4V, the computational formula for the tool-chip contact length presented in Eq. (14) is reliable, although in the literature Eq. (15) is used extensively.

Fig. 16 shows a comparison of the predicted apparent friction coefficient $\mu_{a}$ with experimental data. This parameter was determined from cutting-force measurements; its net variation was small. The model also predicted the shear strains at the primary shear zone, which are compared with experiments in Fig. 17. It can be seen that these shear strains were essentially 0.85 over a wide range of cutting speeds.

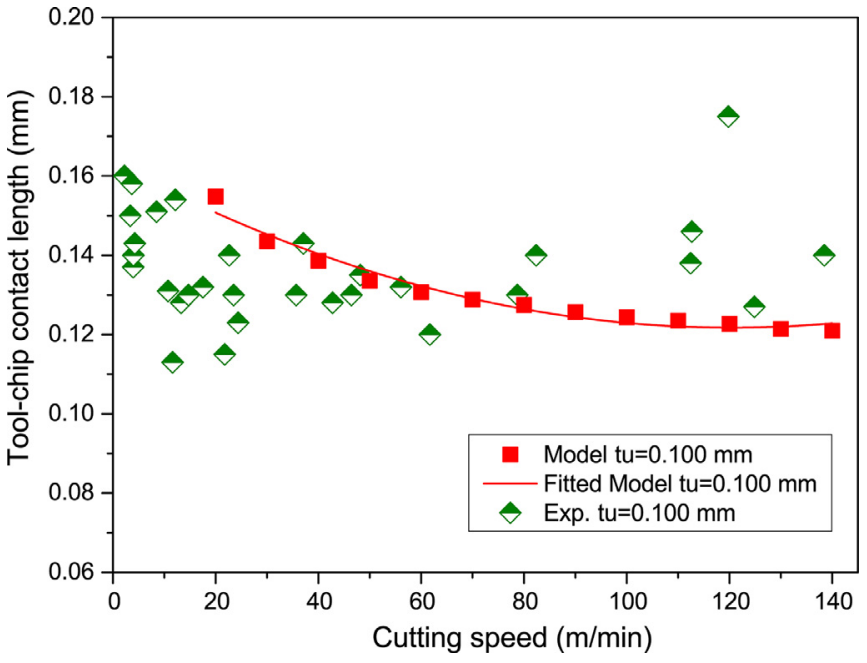

Fig. 15. Comparison of predicted tool-chip contact length with experimental data [37] for different cutting speeds at feed of $0.1 \mathrm{~mm} / \mathrm{rev}$.

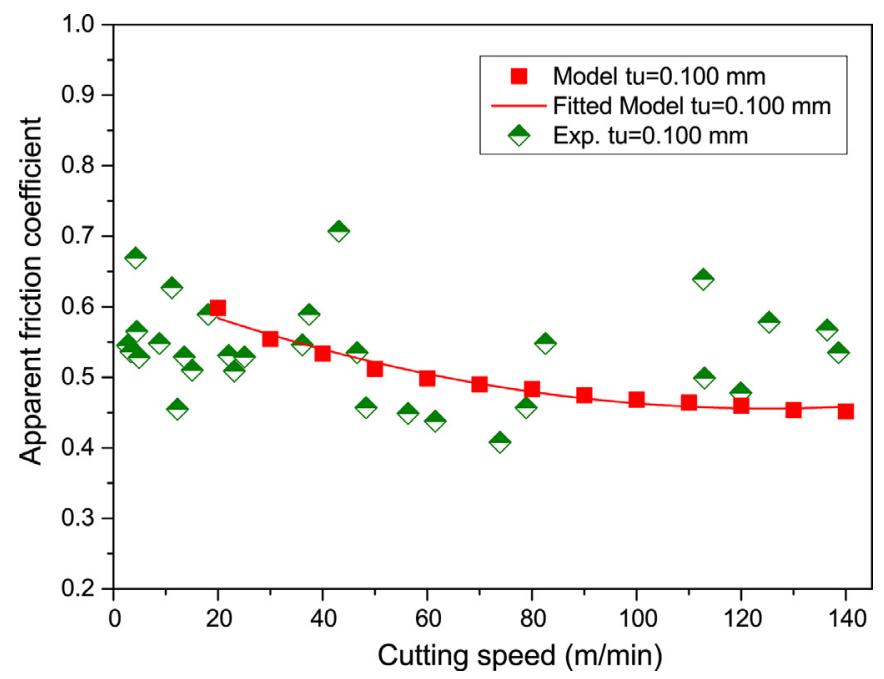

Fig. 16. Comparison of predicted apparent friction coefficient with experimental data [36] for different cutting speeds at feed of $0.1 \mathrm{~mm} / \mathrm{rev}$.

The segmented chip formation is a fundamental phenomenon in machining of Ti6Al4V, with the chip-segmentation frequency $f_{\text {seg }}$ being its main characteristic. The predicted frequency and the experimental data for different cutting speeds at feeds of $0.05,0.075$ and $0.1 \mathrm{~mm} / \mathrm{rev}$ are shown in Fig. 18, with the experimental data obtained from video recordings. The orthogonal cutting tests of Ti6Al4V were recorded with 


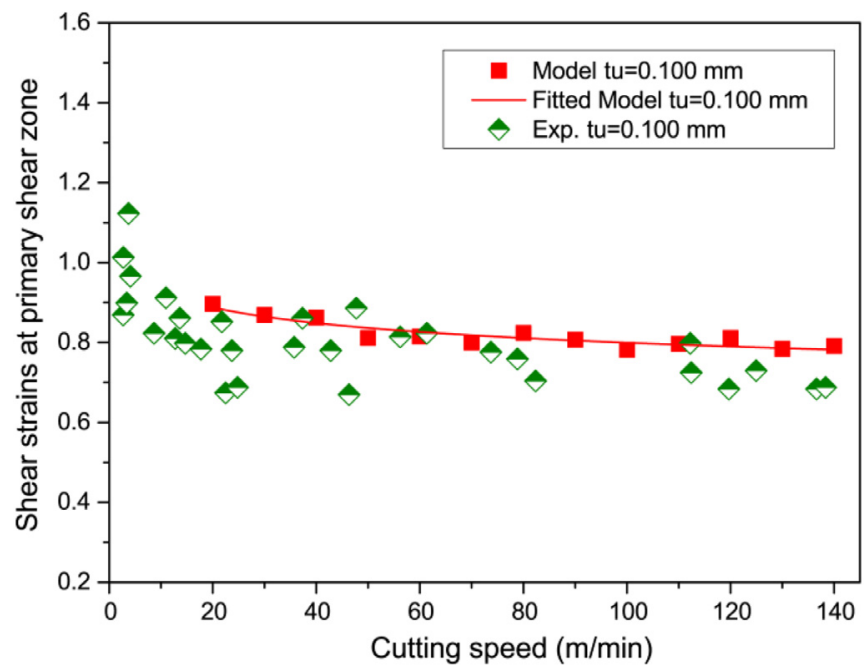

Fig. 17. Comparison of predicted shear strains at primary shear zone with experimental data [37] for different cutting speeds at feed of $0.1 \mathrm{~mm} / \mathrm{rev}$.

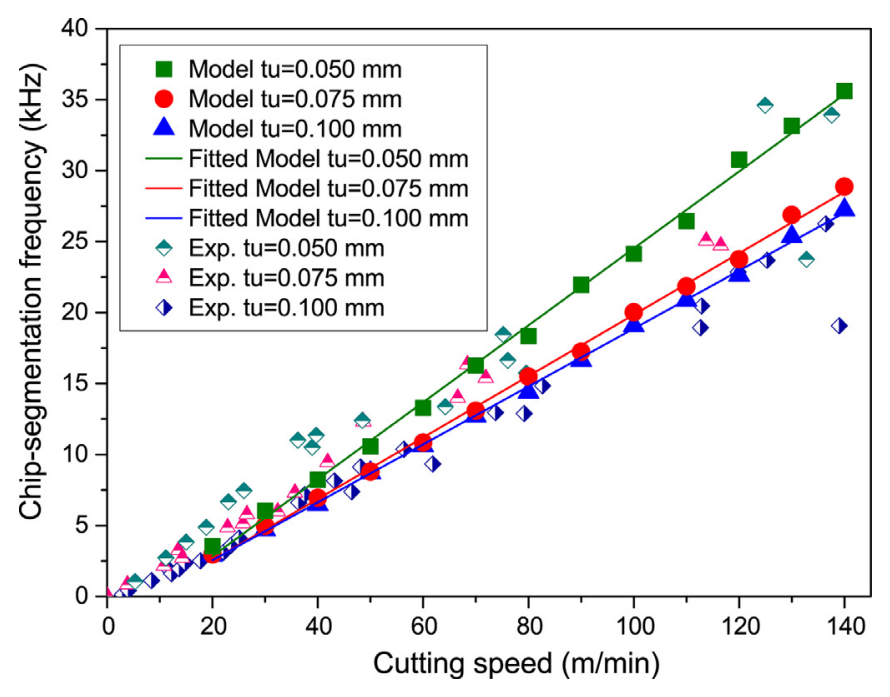

Fig. 18. Comparison of predicted chip-segmentation frequency with experimental data [38] for different cutting speeds at feeds of $0.05,0.075$ and $0.1 \mathrm{~mm} / \mathrm{rev}$.

a high-speed camera with an acquisition frequency of $24 \mathrm{kHz}$, where the chip-segmentation frequency was determined by analysing the video recordings. The predicted results are in good agreement with the experimental results. The chip-segmentation frequency has a significant linear relationship with the cutting speed for in three different feeds, with the chip segmentation frequency increasing linearly with cutting speed and decreasing with feed. In addition, the chip-segmentation frequency for higher feeds shows a similar tendency when compared to smaller depthof-cut (feed) magnitudes.

\section{Conclusions}

In this study, an analytical model of chip formation in orthogonal cutting was proposed for Ti6Al4V. It was used to analyse the primary shear zone, the tool-chip interface and formation of segmented chips. The proposed analytical model can predict both continuous and segmented chip depending on the material and machining conditions.

Conclusions from this study are as follows:

(1) The non-equidistant shear zone model was employed to calculate shear strains and the shear strain rate in the primary shear zone, and the simplified heat transfer equation was used for tempera- ture predictions. This approach was used to assess fields of shear strain, shear strain rate and temperature in the primary shear zone.

(2) The Calamaz-modified Johnson-Cook material model was employed to calculate shear stresses in the primary shear zone; it considered flow softening at high strains and temperaturedependent flow softening as more suitable for the cutting process.

(3) A modified shear-angle solution was presented, which was different from the classical Ernst-Merchant and Lee-Shaffer models. The predicted and experimental magnitudes of shear angle demonstrated adequacy of the suggested scheme.

(4) For the tool-chip interface, two models for the contact length were compared, and the one based on Eq. (14) was found to be better for Ti6Al4V. Additionally, the modified solutions for the equivalent strain and the average temperature rise were validated with the FE results.

(5) The model of segmented-chip formation was developed based on the analysis of geometrical characteristics of the sawtooth chip and used to predict the chip-segmentation frequency.

(6) Comparisons of the results predicted with the suggested analytical approach and the experimental data showed that the cutting forces, the tool-chip contact length, the apparent friction coefficient and shear strains in the primary shear zone decreased gradually with the cutting speed. The shear angle increased with the cutting speed up to $\sim 45^{\circ}$. The chip-segmentation frequency increased linearly with the cutting speed and decreases in feed.

The effect of chip segmentation on transient cutting forces and temperature will be investigated in our future work.

\section{Acknowledgement}

This work was supported by the National Basic Research Program of China (973 Program) grant No. 2013СВ035805. Wei Bai acknowledges a fellowship from the China Scholarship Council.

\section{References}

[1] Oxley, P.L.B., Young, H. The mechanics of machining: an analytical approach to assessing machinability. Ellis Horwood Publisher 1989:136-182.

[2] Ernst H, Merchant ME. Chip formation, friction and finish. Cincinnati: Cincinnati milling mach Co; 1941.

[3] Lee E, Shaffer B. The theory of plasticity applied to a problem of machining. J Appl Mech 1951;18:405-13.

[4] Tounsi N, Vincenti J, Otho A, Elbestawi M. From the basic mechanics of orthogonal metal cutting toward the identification of the constitutive equation. Int J Mach Tools Manuf 2002;42:1373-83.

[5] Adibi-Sedeh AH, Madhavan V, Bahr B. Extension of Oxley's analysis of machining to use different material models. J Manuf Sci Eng 2003;125:656-66.

[6] Lalwani D, Mehta N, Jain P. Extension of Oxley's predictive machining theory for Johnson and Cook flow stress model. J Mater Process Technol 2009;209:5305-12.

[7] Johnson GR, Cook WH. Fracture characteristics of three metals subjected to various strains, strain rates, temperatures and pressures. Eng Fract Mech 1985:21:31-48.

[8] Özel T. The influence of friction models on finite element simulations of machining. Int J Mach Tools Manuf 2006;46:518-30.

[9] Zorev N. Inter-relationship between shear processes occurring along tool face and shear plane in metal cutting. Int Res Prod Eng 1963;49:143-52.

[10] Childs T. Friction modelling in metal cutting. Wear 2006;260:310-18.

[11] Özel T, Zeren E. A methodology to determine work material flow stress and tool-chip interfacial friction properties by using analysis of machining. J Manuf Sci Eng 2006;128:119-29.

[12] Ozlu E, Budak E, Molinari A. Analytical and experimental investigation of rake contact and friction behavior in metal cutting. Int J Mach Tools Manuf 2009;49:865-75.

[13] Molinari A, Cheriguene R, Miguélez H. Numerical and analytical modeling of orthogonal cutting: the link between local variables and global contact characteristics. Int J Mech Sci 2011;53:183-206.

[14] Bahi S, Nouari M, Moufki A, Mansori MEl, Molinari A. Hybrid modelling of slidingsticking zones at the tool-chip interface under dry machining and tool wear analysis. Wear 2012;286:45-54.

[15] Dinzart F, Molinari A. Structure of adiabatic shear bands in thermo-viscoplastic materials. Eur J Mech A/Solids 1998;17:923-38.

[16] Molinari A, Musquar C, Sutter G. Adiabatic shear banding in high speed machining of Ti-6Al-4V: experiments and modeling. Int J Plasticity 2002;18:443-59.

[17] Hou ZB, Komanduri R. Modeling of thermomechanical shear instability in machining. Int J Mech Sci 1997;39:1273-5, 1277-1281, 1283, 1285-1314. 
[18] Fourment L, Delalondre F. A 3D study of the influence of friction on the adiabatic shear band formation during high speed machining. Int $\mathrm{J}$ Mater Form 2008;1:1415-18.

[19] Bäker M, Rösler J, Siemers C. A finite element model of high speed metal cutting with adiabatic shearing. Comput Struct 2002;80:495-513.

[20] Hua J, Shivpuri R. Prediction of chip morphology and segmentation during the machining of titanium alloys. J Mater Process Technol 2004;150:124-33.

[21] Ducobu F, Rivière-Lorphèvre E, Filippi E. Numerical contribution to the comprehension of saw-toothed Ti6Al4V chip formation in orthogonal cutting. Int J Mech Sci 2014;81:77-87.

[22] Miguélez M, Soldani X, Molinari A. Analysis of adiabatic shear banding in orthogonal cutting of Ti alloy. Int J Mech Sci 2013;75:212-22.

[23] Liu R, Melkote S, Pucha R, Morehouse J, Man X, Marusich T. An enhanced constitutive material model for machining of Ti-6Al-4V alloy. J Mater Process Technol 2013;213:2238-46.

[24] Astakhov VP, Osman M, Hayajneh M. Re-evaluation of the basic mechanics of orthogonal metal cutting: velocity diagram, virtual work equation and upper-bound theorem. Int J Mach Tools Manuf 2001;41:393-418.

[25] Li B, Wang X, Hu Y, Li C. Analytical prediction of cutting forces in orthogonal cutting using unequal division shear-zone model. Int J Adv Manuf Technol 2011;54:431-43.

[26] Bai W, Sun R, Gao Y, Leopold J. Analysis and modeling of force in orthogonal elliptical vibration cutting. Int J Adv Manuf Technol 2016;83:1025-36.

[27] Gao Y, Sun R, Chen Y, Leopold J. Mechanical and thermal modeling of modulation-assisted machining. Int J Adv Manuf Technol 2016;86:2945-59.

[28] Lee WS, Lin CF. Plastic deformation and fracture behaviour of Ti-6Al-4V alloy loaded with high strain rate under various temperatures. Mater Sci Eng 1998;241:48-59.

[29] Seo S, Min O, Yang H. Constitutive equation for Ti-6Al-4V at high temperatures measured using the SHPB technique. Int J Impact Eng 2005;31:735-54.

[30] Meyer HW, Kleponis DS. Modeling the high strain rate behavior of titanium undergoing ballistic impact and penetration. Int J Impact Eng 2001;26:509-21.

[31] Calamaz M, Coupard D, Girot F. A new material model for 2D numerical simulation of serrated chip formation when machining titanium alloy Ti-6Al-4V. Int J Mach Tools Manuf 2008;48:275-88.

[32] Sima M, Özel T. Modified material constitutive models for serrated chip formation simulations and experimental validation in machining of titanium alloy Ti-6Al-4V. Int J Mach Tools Manuf 2010;50:943-60.

[33] Fu Z, Zhang X, Wang X, Yang W. Analytical modeling of chatter vibration in orthogonal cutting using a predictive force model. Int J Mech Sci 2014;88:145-53.
[34] Grzesik W. Advanced machining processes of metallic materials: theory, modelling and applications. Elsevier; 2008.

[35] Moufki A, Molinari A, Dudzinski D. Modelling of orthogonal cutting with a temperature dependent friction law. J Mech Phys Solids 1998;46:2103-38.

[36] Cotterell M, Byrne G. Imaging and analysis of chip formation during orthogonal cutting of titanium alloy Ti-6Al-4V. Int J Nano Biomater 2007;1:65-75.

[37] Cotterell M, Byrne G. Characterisation of chip formation during orthogonal cutting of titanium alloy Ti-6Al-4V. CIRP J Manuf Sci Technol 2008;1:81-5.

[38] Cotterell M, Byrne G. Dynamics of chip formation during orthogonal cutting of titanium alloy Ti-6Al-4V. CIRP Ann-Manuf Technol 2008;57:93-6.

[39] Budak E, Ozlu E. Development of a thermomechanical cutting process model for machining process simulations. CIRP Ann-Manuf Technol 2008;57:97-100.

[40] Mathew P, Oxley P. Predicting the effects of very high cutting speeds on cutting forces, etc. CIRP Ann-Manuf Technol 1982;31:49-52.

[41] Yamaguchi K, Yamada M. Stress distribution at the interface between tool and chip in machining. J Eng Ind-T ASME 1972;94:683-9.

[42] Trent EM, Wright PK. Metal cutting. Butterworth-Heinemann; 2000.

[43] Childs T. Metal machining: theory and applications. Butterworth-Heinemann; 2000

[44] Bahi S, Nouari M, Moufki A, Mansori MEl, Molinari A. A new friction law for sticking and sliding contacts in machining. Tribol Int 2011;44:764-71.

[45] Bai W, Sun R, Leopold J, Silberschmidt VV. Microstructural evolution of Ti6Al4V in ultrasonically assisted cutting: numerical modelling and experimental analysis. Ultrasonics 2017;78:70-82.

[46] Bai W, Sun R, Leopold J. Numerical modelling of microstructure evolution in Ti6Al4V alloy by ultrasonic assisted cutting. Procedia CIRP 2016;46:428-31.

[47] Boothroyd G. Temperatures in orthogonal metal cutting. Proc Inst Mech Eng 1963;177:789-810.

[48] Stevenson MG, Oxley P. An experimental investigation of the influence of strain-rate and temperature on the flow stress properties of a low carbon steel using a machining test. P I Mech Eng 1970;185:41-754.

[49] Sutter G, List G. Very high speed cutting of Ti-6Al-4V titanium alloy-change in morphology and mechanism of chip formation. Int J Mach Tools Manuf 2013;66:37-43.

[50] Wang C, Xie Y, Zheng L, Qin Z, Tang D, Song Y. Research on the chip formation mechanism during the high-speed milling of hardened steel. Int J Mach Tools Manuf 2014;79:31-48.

[51] He N, Lee T, Lau W, Chan S. Assessment of deformation of a shear localized chip in high speed machining. J Mater Process Technol 2002;129:101-4. 